Patrick M. Wright, John J. Haggerty ${ }^{*}$

\title{
Missing Variables in Theories of Strategic Human Resource Management: Time, Cause, and Individuals
}

Much progress has been made with regard to theory building and application in the field of Strategic Human Resource Management (HRM) since Wright and McMahan's (1992) critical review. While researchers have increasingly investigated the impact of HR on economic success within the Resource Based view of the firm, and have developed more middle level theories regarding the processes through which HR impacts firm performance, much work still needs to be done. This paper examines how future theorizing in SHRM should explore the concepts of time, cause, and individuals. Such consideration will drive more longitudinal research, more complex causal models, and consideration of multi-level phenomena.

Key words: Human Resource Management, Strategic HRM, Firm Performance

Patrick M. Wright, Professor of HR Studies, Director, Center for Advanced HR Studies, School of ILR, Cornell University, Ithaca, NY 14853-3901, USA, Phone: ++1 607255 3429, Fax: ++1 607255 1836, e-mail: pmw6@cornell.edu.

John J. Haggerty, School of ILR, Cornell University, Ithaca, NY 14853-3901, USA, Phone: ++1 315364 5831, Fax: ++1 607255 1836, e-mail: jjh56@cornell.edu.

** This paper was based on a presentation at the Conference honoring Wolfgang Weber's contributions to the field of HRM. Support for the writing of the paper was provided by the Center for Advanced Human Resource Studies (CAHRS) in the School of Industrial Relations at Cornell University.

** Article received: February 27, 2004

Revised version accepted after double blind review: February 7, 2005. 
"Categorization of data - whether qualitative or quantitative - is not theory. Categorization characterizes much of the work... in the realms of business policy/strategy and human resource strategy. "

Samuel Bacharach $(1989,497)$

The fact that a firm's people are becoming central to strategic decision-making seems reasonably unarguable. Strategic Human Resource Management (HRM) researchers have devoted considerable effort toward demonstrating that the ways that people are managed, particularly through HR practices, have strong empirical relationships with organizational performance (Delery/Doty 1996; Huselid 1995; MacDuffie 1995).

While this empirical attention continues to increase, many researchers have criticized the theoretical underpinnings of the research and called for more specific theoretical models of the processes through which HR practices impact organizational performance (Becker/Gerhart 1996; Dyer/Reeves 1995; Guest 1997; Wright/Gardner 2003). While some strides have been made in conceptually articulating mediating processes between HR practices and organizational performance (e.g., Truss/Gratton 1994; Becker/Huselid/Pickus/Spratt 1997), this literature still leaves room for improvement.

The purpose of this paper is to provide an overview of the current status of theoretical development in the HR-performance relationship, and to propose 3 important variables that are currently missing in theoretical analyses of the relationship between HRM and economic success: time, cause, and individuals.

\section{Theory on the Relationship between HRM and Economic Success}

Theory on the relationship between HRM and economic success has grown significantly over the past 15 years. This theoretical progress can be seen in two different arenas: meta-theories describing broad rationales for why HRM and economic success should be linked, and middle-level process theories describing how this linkage takes place.

In the first arena, Wright and McMahan (1992) critically reviewed the state of theory in SHRM research, noting that much research was at best "borrowing" metatheories from other disciplines, and at worst, almost completely atheoretical. At that time they noted that the existing research in SHRM had predominantly utilized Resource -Based Theory, the Behavioral Approach, Open Systems Theory, and Control Theory with a few authors exploring Population Ecology and Critical Theory. They noted then, that this state of affairs could signal a tremendous obstacle to future research. McMahan, Virick, and Wright (1999) updated the earlier Wright and McMahan (1992) review, and found that the Resource-Based View of the Firm had become almost the universally embraced meta-theory among Strategic HRM researchers, largely because of both its popularity in the broader strategy literature, and its ability to articulate why HRM could be linked to the economic success of firms.

For instance, Wright, Dunford, and Snell (2001) provided a comprehensive Resource Based model depicting the relationship between HRM practices and the stock of human capital, the flow of knowledge, and the dynamic capabilities of firms, all of which have been advocated among strategy researchers as important resources for 
competitive success. While this model provides an integrative framework of why HRM might be linked to economic success within the Resource Based View of the firm it does not necessarily meet the level of a theory of strategic HRM.

The problem with these "meta-theories" of the relationship between HRM and economic success lies with the failure to specifically articulate the processes through which the relationship occurs. In essence, the meta-theory provides an overarching rationale for why HRM and economic success might be linked, but researchers must then develop a more specific theoretical story that describes specific mediating processes.

In this vein, McMahan, Virick, and Wright (1999) found that researchers were more consistently grounding their investigations in established meta-theoretical frameworks, but then developing middle level process theories for explaining the impact of HR practices on firm performance. For example, one of the more thorough models of SHRM was proposed by Becker, Huselid, Pickus, and Spratt, (1997). These authors ground their rationale for how HR practices would drive economic success within the meta-theory of the Resource Based View of the Firm. They then develop a more specific process model suggesting that the firm's strategy dictates the design of the HR system. The HR system impacts the employee skills and motivation, which, in turn, results in creativity, productivity, and discretionary behavior. Employees' behavior influences the firm's operating performance, which leads to profitability, growth, and market value.

Wright and Gardner (2003) used this theoretical model to describe some additional problems in research and theory on the HRM - economic success relationship. They noted that inherent in any theoretical attempt to describe the process through which HRM drives economic success is the question of micro-mediation. Micromediation describes the fact that the linkage between any two process mechanisms can be more specifically described by many more specific subprocesses. Thus, theoreticians will always face the problem of describing a process at one level of detail that leave itself open to criticism for not describing a finer level of detail.

This paper seeks neither to develop a new meta-theory nor a new process theory of the relationship between HRM and economic success. Rather, it seeks to step back from the current efforts and identify some of the key variables that seem to be missing or ignored in current attempts to theoretically articulate this relationship. In doing so, we suggest that the future theory might benefit considerably from considering three important concepts: time, cause, and individuals.

\section{Time and the Relationship Between HRM and Economic Success}

Current theory exploring the relationship between HRM and economic success has not deeply considered temporal issues. In most cases, time is either assumed as a constant, or considered in a relatively shallow way.

Meta-theories such as the resource-based view indirectly consider time, usually suggesting that competitive advantages stemming from HRM evolve over long time periods. In addition, time comes into play with regard to "sustainable" competitive advantages as authors such as Barney (1990) note that the concept requires an advantage that is held over some segment of time. However, the time component is only 
explored indirectly, and in fact, Barney tries to avoid specifying a time by noting that sustainability is defined when other firms have given up on imitating the advantage. This sidestepping of exploring temporal issues in unfortunate. For instance, if a system of practices that results in competitive advantage evolves over time, it seems important to specify both the amount of time and the process through which this evolution occurs if one want to deeply understand how those practices result in economic success.

Even less well developed is the concept of time within process theories of this relationship. These models, through the use of causal arrows, implicitly suggest temporal precedence from one concept to the next, but do not specifically explore temporal lags. For instance, returning to the model proposed by Becker et al, (1997) which proposes that strategy impacts HRM practices, with successive sequential impact on employee behavior, operational performance, profitability and finally, shareholder value.

With regard to the first (strategy-HRM) link, Wright, Dyer, and Takla (1999) specifically explored time lags in the implementation of HRM practices. They asked over 70 HR VP's to assume that a major strategic change necessitated a significant overhaul of their firm's HRM systems. They asked them to estimate (a) the time it would take to design (know what practices would have to be implemented) the new system and (b) the time it would take to deliver (have them up and running, but not necessarily having any impact) the new system. These executives provided an average estimate of 9-10 months for the design, and an additional 10-12 months for the delivery of these systems. This supports the relative intractability of HRM systems (Snell 1994; Wright/Snell 1998). Note that the subsequent links in the causal chain (e.g., how long before the practices start to impact employee behavior? How long until employee behavior results in increased operating performance? Etc.) are not addressed. If the first link in the causal chain takes almost two years, it is not unreasonable to expect a 3-4 year total time lag before the relationship would be observed. Clearly, current theoretical models do not account for such a time length.

This temporal lag between HRM and economic success becomes even more apparent when one considers the current empirical research exploring the relationship between HRM and economic success. For instance, Wright, Gardner, Moynihan, and Allen (in press) conducted a literature review identifying 67 empirical studies (with 69 different designs) examining the relationship between multiple HR practices and performance. They classified these studies by the type of temporal design used. By far the most prevalent design within the literature examining the HR - performance relationship was termed "post-predictive," because it measures HR practices after the performance period, resulting in those practices actually predicting past performance. Many of these designs entail a single data collection effort where the same respondent provides information for both assessments of their current HR practices and their firms' performance. This design accounted for 50 of the 69 observed designs. A second type of design was referred to as "retrospective" because it asked respondents to recall HR practices that existed prior to the performance period. Six of the studies used this design. Third, four "contemporaneous" studies gathered contemporaneous HR practice and performance data (e.g., gathering data during 2003 and then using 2003 performance measures). Finally, only a few "predictive" studies have explored if 
practices assessed at one point in time were related to subsequent firm performance. Such designs are the only designs that accurately consider time, but have been used in only 9 studies. In summary, all but 9 empirical studies on the link between HRM and economic success have incorrectly considered temporal issues.

One final way in which time has been considered theoretically was with regard to the concept of "flexibility." Wright and Snell (1998) argued that "fit" can only be considered at a single point in time, and that flexibility requires demonstrating multiple successive fits over time. They examined flexibility with regard to employee skills, employee behavior, and HR practices, and specifically noted that variance likely exists in the extent to how quickly some HRM practices can be changed as well as how quickly some might impact employee behavior. This exploration of flexibility presents an attempt, albeit inadequate, to bring the concept of time into our understanding of the relationship between HRM and economic performance.

Given the increasingly fast pace of environmental and organizational change, the seeming lack of attention to temporal issues with regard to HRM seems short sighted. However, this area seems ripe for future theoretical and empirical analysis. However, note that the current treatments of time within theoretical work on the link between HRM and economic success all assume a uniform causal direction with the HRM driving success. To this issue we turn next.

\section{Cause and the Relationship Between HRM and Economic Success}

As previously discussed temporal issues have been largely ignored in theoretical analyses of the HRM - economic success relationship. Another glaring consequence of this oversight ties directly into attempts to explore the causal relationship between HRM and economic success because temporal precedence serves as a precondition to inferring cause.

Cook and Campbell (1979) provide an in-depth analysis of how philosophers of science have approached the issue of demonstrating a causal relationship. Based on the work of John Stuart Mill, they propose three criteria for inferring cause: Covariation between the presumed cause and effect, the temporal precedence of the cause, and the ability to control or rule out alternative explanations for a possible cause and effect connection. However, the research on the impact of HR practices on economic success has precluded drawing firm causal conclusions regarding this relationship, and in fact, may support a reverse causation hypothesis, with economic success leading to better HRM.

Wright, et al.'s (in press) review of the literature on the relationship between HR and economic success and concluded that it has (a) universally reported significant relationships between HR and performance, (b) almost exclusively used designs that do not logically allow one to draw causal conclusions, and (c) very seldom actually tested for a reverse causal order. In addition, in the few cases where the studies tested for reverse causal order, evidence suggests questioning the assumption of an HRM performance causal ordering. For example, Guest, Michie, Conway, and Sheehan (2003) related HR practices to objective productivity and profitability data (both past and subsequent) as well as current subjective productivity and financial performance estimates among a sample of 366 companies in the U.K. Their results suggested that HR practices were related to higher profitability but not productivity, but that the 
practices were related to higher profitability but not productivity, but that the significant relationship with profitability disappeared after controlling for past performance. They concluded that there was a relationship between HRM and performance, but that their results failed to demonstrate that HR causes higher performance.

More recently, using data from 45 business units, Wright et al. (in press) examined how measures of HR practices correlated with past, concurrent, and future operational performance measures. They found that correlations with performance measures at all three times were both high and invariant, and that controlling for past or concurrent performance virtually eliminated the correlation of HR with future performance. They concluded that while their data could not prove any causal direction, it provided just as much evidence for a Performance - HR causal chain as for an HR - performance sequence.

The "cause" question presents some interesting theoretical avenues for understanding the relationship between HRM and economic success. For instance, "reverse causation" would suggest that, rather than HR practices causing economic success, success causes HR practices. Highly successful organizations, by their nature possess slack resources. Profitable firms may share these profits with employees in a number of ways. They may provide higher pay and benefits, invest in offering more training and development opportunities, develop more extensive selection systems, and/or allow employees to participate in teams, quality circles, and other forms of empowerment activities.

In fact, a number of the HR practices more logically demonstrate a reverse causation effect. Practices measured in this vein of research such as the percentage of total pay which is variable, the differences in percent merit increases between high and low performers, and the number of hours training received are heavily influenced by the past and current financial performance of a firm. Firms facing financial difficulties reduce their variable pay (profit sharing and stock options have little or no value) (Hewitt Associates 2001; Kennedy 2003), merit increases (and thus the difference between high and low performers) (Gomez-Mejia et al. 2004; Kennedy 2003), and training budgets (reduce the number of hours they train employees) (Exclusive RSS Suvey 2003; McIntyre 1992).

From a theoretical standpoint, current endeavors to explore the HRM - economic success relationship seldom address the potential for anything other than a oneway causal direction. However, recent research suggests that at best, a dual causality relationship might exist, and at worst, the one-way relationship advocated in current theory is actually the wrong way (Guest et al. 2003; Wright et al. in press). Consequently, future theory development could benefit greatly from a more deliberate approach to addressing cause in the relationship between HRM and economic performance. This suggests the need for more complex theoretical models. One aspect of the complexity may be to recognize individual level phenomena within the causal chain.

\section{Individuals in the Relationship between HRM and Economic Success}

The final area of future theoretical attention stems from implicit centrality of individuals and individual level phenomena within models of the relationship between HRM 
and economic success. This issue reflects the levels of analysis tension inherent in research on people in organizations. At the organization or unit level, theories seek to explain how variation in one unit level variable relates to variation in another unit level variable. However, often one or both of these unit level variables deal with aggregated individuals, and variance across individuals, both its cause and effect, is lost.

Consider Becker, et al's (1997) model arguing that HR practices drive employee behavior, operational performance, profitability, and ultimately shareholder value. Note that of all these variables, most research has only focused on two that are quite distal from one another in the causal chain (HR practices and performance). Note also that because the level of analysis is the firm (or plant), the model seems to assume uniformity or constancy with regard to each variable (i.e., there is no variation within firm in HR practices, no variation within firm in employee reactions, etc.). This is not to criticize the assumption, because such assumptions are always necessary with regard to one level of analysis. However, in order to increase our understanding of how HR practices impact performance, we might benefit greatly from approaching the issue in a multi-level framework (Ostroff/Bowen 2000; Bowen/Ostroff 2004).

Wright and Nishii (2004) conceptually examined some of the mediating processes that might occur in the HRM - performance relationship by examining the relationship at multiple levels of analysis. They suggested that virtually all existing SHRM research focuses on variance at one level of analysis while assuming constancy at other levels. They proposed that attending to some of the relevant variables that have been heretofore virtually ignored in the empirical SHRM literature would increase our theoretical understanding of the linkage between HRM and economic performance. Presenting a process model that included intended HR practices, actual HR practices, perceived HR practices, employee reactions, and performance, they noted that the perceived HRM practices and employee reactions are actually individual-level variables that are central to the proposed causal process, yet are currently ignored in unit-level theories of strategic HRM.

According to their model, the actual HR practices exist objectively, yet must be perceived and interpreted subjectively by each employee in the focal group. Consequently, the process then moves down to the level of the individual. At this level considerable variance can occur for two primary reasons. First, because there may be variation in the actual HR practices (e.g., different supervisors varying in their implementation of the practice(s)), that variation would likely cause valid variance in perceived HR practices. Second, because individuals have their own schemas for attending to and processing information, additional variance should occur at this level (Rousseau 2001).

Then, based on the perceived HR practices, employees will react in some way. Each employee processes the information in a way that elicits some reactions, be they affective (attitudinal), cognitive (knowledge or skill) and/or behavioral. Affective reactions consist of reactions such as various aspects of job satisfaction and/or organizational commitment. Cognitive reactions may include increased knowledge or skill. Behavioral reactions can be classified as reactions with regard to task, counterproductive, and discretionary behavior. Task behavior describes the kind of behavior prescribed as part of the job. Increasing job focused behavior aimed at being more productive or 
making fewer mistakes exemplify task behavior. Counterproductive behavior describes negative behavior aimed at either hurting the organization or at bettering ones' own position at the expense of the organization. Theft of goods, sabotage, or time theft (e.g., spending work time on personal activities) exemplify counterproductive behavior. Discretionary behavior consists of behavior not prescribed by the organization, but which is aimed at benefiting the organization. Going beyond job duties to satisfy a customer, routinely skimming academic or practitioner journals, or performing nonprescribed preventative maintenance on a machine would be examples of discretionary behavior. These two steps in the causal chain highlight the centrality of individual level phenomena in organizational level processes.

While not addressing this issue directly, recent research has demonstrated some support for the importance of recognizing variance in how individuals form their impressions of HR practices. For example, Nishii (2003) examined the relationship between employees' attributions for HR practices (the goals that they perceived as underlying certain HR practices), organizational commitment/satisfaction, OCBs, and ultimately customer satisfaction in a largely unionized sample where the HRM practices were quite uniform across units. At the unit level she found that considerable variance in unit-level customer satisfaction can be explained by differences in HR attributions across units.

This discussion suggests the need for more multi-level theories of the relationship between HRM and economic performance. Multi-level theories seek to simultaneously explain variance at multiple levels of analysis (e.g., individual, group, and organization). Bowen and Ostroff (2004) have developed the most extensive multi-level model of SHRM to date. Their theoretical approach argues that HR practices serve as communications mechanism signaling employees to engage in certain behaviors. Consequently, they rely on communications theory for examining different aspects of the HRM systems that may impede or facilitate this communication process. While their approach currently provides the most comprehensive attempt to integrate organizational and individual processes, additional theoretical contributions can be made.

One approach would be to develop comprehensive theories that integrate across levels of analysis. Such a theory would attempt to link organizational concepts to individual concepts back to other organizational concepts. While such an allencompassing theory would be desirable, it may not be feasible.

Alternatively, one could attempt to develop more specific cross-level theories that explain smaller aspects of the linkage between organizational and individual phenomena. Bowen and Ostroff's (2004) attempt to link HR practices to employee reactions via communications theory illustrates this approach. In addition, theories and research on issues such as schemas/cognitive processes, social information processing, individual differences, and motivation theories can provide valuable explanation to the individual processes that are being triggered by organizational level HRM practices.

\section{Conclusion}

The recent advances in theoretical understanding of the relationship between HRM and economic performance bode well for the future of the field. Middle level process 
theories embedded within larger meta-theories such as the Resource Based View of the firm have provided an essential foundation for further theoretical advances.

We believe that advances can come from extending the current work to examine the concepts of time, cause, and individuals more thoroughly. Such theoretical examination can serve as an essential starting point for building a more robust empirical base that will significantly increase our knowledge of the relationship between HRM and economic performance.

\section{References}

Bacharach, S. (1989): Organization Theories: Some criteria for evaluation. In: Academy of Management Review, 14: 496-515.

Barney, J. (1991) Firm resources and sustained competitive advantage. In: Journal of Management, 17: 99120.

Becker, B./Gerhart, G. (1996): The impact of human resource management on organizational performance: Progress and prospects. In: Academy of Management Journal, 39: 779-801.

Becker, B./Huselid, M./Pickus, P./Spratt, M. (1997): HR as a Source of Shareholder Value: research and Recommendations. In: Human Resource Management, 36(1): 39

Bowen, D./Ostroff, C. (2004): Understanding HRM-Firm Performance Linkages: The Role of the Strength of the HRM System. In: Academy of Management Review, 29(2): 203-221

Cook, D./Campbell, D. (1979): Quasi-Experimentation. Holt-Rinehart: New York.

Delery, J. E./Doty, D. H. (1996): Modes of theorizing in strategic human resource management: Tests of universalistic, contingency and configurational performance predictions. In: Academy of Management Journal, 39: 802-835.

Dyer, L./Reeves, T. (1995): HR strategies and firm performance: What do we know and where do we need to go. In: International Journal of Human Resource Management, 6: 656-670.

Exclusive RSS survey reveals Top 15 ways to cut compensation costs. In: Report on Salary Surveys, 3(12): $1-7$.

Gerhart, B./Wright, P./McMahan, G. (2000): Measurement Error and Estimates of the HR - Firm Performance Relationship: Further Evidence and Analysis. In: Personnel Psychology, 53: 855-872

Gerhart, B./Wright, P./McMahan, G./Snell, S. (2000): Research on human resource decisions and firm performance: How much error is there, and how does it influence effect size estimates? In: Personnel Psychology, 53: 803-834.

Gomez-Mejia, L./Larraza-Kintana, M./Makri, M. (2004): The determinants of executive compensation in family controlled public corporations. In: Academy of Management Journal, 46(2): 226

Guest, D. (1997): Human resource management: When research confronts theory. In: International Journal of Human Resource Management, 12(7): 1092-1106.

Guest, D./Michie, J./ Conway, N./Sheehan, M. (2003): Human resource management and corporate performance in the UK. In: British Journal of Industrial Relations, 41: 291-314.

Hewitt Associates (2001): Survey of Economic Impact Due to Current Events. www.Hewitt.com

Huselid, M. A. (1995): The impact of human resource management practices on turnover, productivity, corporate financial performance. In: Academy of Management Journal, 38: 635-672.

Huselid, M. A./Becker, B. E. (1996): Methodological issues in cross-sectional and panel estimates of the human resource-firm performance link. In: Industrial Relations, 35: 400-422.

Kennedy, P. (2003): Redefining compensation in challenging times. In: Employee Benefits Journal, 28(3): 63.

MacDuffie, J. P. (1995): Human resource bundles and manufacturing performance: Organizational logic and flexible production systems in the world auto industry. In: Industrial and Labor Relations Review, 48: 197-221.

McMahan, G./Virick, M./Wright, P. (1999): Alternative theoretical perspectives for SHRM: Progress, Problems, and prospects. In: Wright, P./Dyer, L./Boudreau, J./Milkovich, G. (eds.): Research in Personnel and Human Resource Management (Supplement 4): 99-122. Greenwich, CT: JAI Press. 
McIntyre, D. (1992): Training Budgets weather the Recession. In: Canadian Business Review, 19(2): 3335.

Nishii, L.H. (2003): The psychology of strategic human resource management: The effect of employee attributions for HR practices on unit satisfaction, commitment, organizational citizenship behaviors, and customer satisfaction. Unpublished dissertation, University of Maryland.

Ostroff, C./Bowen, D. E. (2000): Moving HR to a higher level: HR practices and organizational effectiveness. In: K. K. Klein/S. W. J. Kozlowski (eds.): Multilevel theory, research, and methods in organizations: Foundations, extensions and new directions. San Francisco, CA: Jossey-Bass.

Rousseau, D. M. (2001): Schema, promise and mutuality: The building blocks of the psychological contract. In: Journal of Occupational and Organizational Psychology, 74: 511-541.

Snell, S./Dean, J. (1994): Strategic compensation for integrated manufacturing: The moderating effects of jobs and organizational inertia. In: Academy of Management Journal, (37)5: 1109.

Truss, C./Gratton, L. (1994): Strategic human resource management: A conceptual approach. In: The International Journal of Human Resource Management, 5(3): 663-686.

Wright, P./Dunford, B./Snell, S. (2001): Contributions of the Resource Based View of the Firm to the Field of Strategic HRM: Convergence of two Fields. In: Journal of Management, 27: 701-721.

Wright, P. M./Dyer, L. D./Takla, M. G. (1999): What's Next? Key Findings from the 1999 State of the Art \& Practice Study. In: Human Resource Planning, 22(4): 12-20.

Wright, P./Boswell, W. (2002): Desegregating HRM: A Review and Synthesis of Micro and Macro Human Resource Management Research. In: Journal of Management, 28: 247-276.

Wright, P. M./Gardner, T./Moynihan, L. (2003): The impact of human resource practices on business unit operating and financial performance. In: Human Resource Management Journal, 13(3): 21.

Wright, P./Gardner, T./Moynihan, L./ Park, H./Gerhart, B./Delery, J. (2001): Measurement Error in Research on Human Resources and Firm Performance: Additional Data and Suggestions for Future Research. In: Personnel Psychology, 54: 875-902.

Wright, P./Gardner, T./Moynihan, L./Allen, M. (conditionally accepted): The HR - performance relationship: Examining causal direction. In: Personnel Psychology.

Wright, P. M./McMahan, G. C. (1992): Theoretical perspectives on strategic human resource management. In: Journal of Management, 18: 295-320.

Wright, P./Nishii, L. H. (2004): Strategic HRM and Organizational Behavior: Integrating Multiple Levels of Analysis. Paper presented at the Erasmus University Conference "HRM: What's Next?"

Wright, P./Sherman, S. (1999): Failing to find fit in strategic human resource management: Theoretical and empirical problems. In: Wright, P./Dyer, L./Boudreau, J./Milkovich, G. (eds.): Research in Personnel and Human Resource Management (Supplement 4): 53-74. Greenwich, CT: JAI Press.

Wright, P. M./Smart, D. L./McMahan, G. C. (1995): Matches between human resources and strategy among NCAA basketball teams. In: Academy of Management Journal, 38: 1052-1074.

Wright, P./Snell, S. (1998): Toward a unifying framework for exploring fit and flexibility in strategic human resource management. In: Academy of Management Review, 23(4): 756-772. 